\title{
Peripheral blood lymphocyte subpopulations in patients with primary proliferative and secondary polycythaemia
}

\author{
J T WILDE, D BARNETT, M J FORREST, A C K LAWRENCE \\ From the Department of Haematology, The Northern General Hospital, Sheffield
}

SUMMARY Peripheral blood lymphocyte subpopulations were measured in 18 patients with primary proliferative polycythaemia and 13 patients with secondary polycythaemia. A decrease in numbers of suppressor $\mathrm{T}$ lymphocytes and an increase in the helper:suppressor $\mathrm{T}$ lymphocyte ratio was found in those with primary polycythaemia compared with normal subjects and patients with secondary polycythaemia. If other causes of an increased helper:suppressor ratio are excluded this variable may be useful in confirming the myeloproliferative nature of patients with erythrocytosis.

In 1983 Eridani et al reported a study of peripheral blood lymphocyte subpopulations in patients with primary proliferative polycythaemia and idiopathic erythrocytosis. ${ }^{1}$ They found that in both groups there was a decrease in total numbers of Tlymphocytes, with a particular decrease in the suppressor lymphocytes compared with the numbers seen in normal controls, so that the helper:suppressor T lymphocyte ratio was increased.

We performed a study of peripheral blood lymphocyte subpopulations in patients with primary proliferative and secondary polycythaemia to determine whether the helper:suppressor Tlymphocyte ratio differed between the two groups.

\section{Material and methods}

SELECTION OF PATIENTS

New and follow up patients with primary proliferative and secondary polycythaemia attending the outpatient departments at the Northern General and Royal Hallamshire Hospitals, Sheffield were studied.

\section{Primary proliferative polycythaemia}

Primary proliferative polycythaemia was diagnosed in patients fulfilling the following criteria: raised haematocrit and increased red cell volume, as measured by the ${ }^{51} \mathrm{Cr}$ dilution technique giving values greater than $25 \%$ of the expected value adjusted for height and weight ${ }^{2}$; together with the presence of at least two of the following variables, splenomegaly, increased neutrophil and platelet counts, and an increased leucocyte alkaline phosphatase value. These criteria differ slightly from those laid down by the Polycythaemia Vera Study Group. ${ }^{3}$

Our group contained 18 patients, 10 men and eight women, with a mean age of 63 years (range 31-89). Twelve of them had been diagnosed within the previous five years, and the remaining six had been diagnosed at varying times prior to this. Seven had well documented splenomegaly at some time during their disease; eight had received at least one injection of ${ }^{32} \mathrm{P}$; and another three had required intermittent courses of busulphan to control their disease over the time before the study started. A further three patients had been controlled by venesection only. The remaining three were included in the study at the time of diagnosis.

\section{Secondary polycythaemia}

Secondary polycythaemia was diagnosed in patients with the following criteria: haemoglobin equal to or greater than $19 \mathrm{~g} / \mathrm{dl}$; packed cell volume equal to or greater than $60 \%$ in men and haemoglobin concentration equal to or greater than $18 \mathrm{~g} / \mathrm{dl}$; packed cell volume equal to or greater than $55 \%$ in women and in patients having a clear cut disorder associated with secondary polycythaemia. It was impossible to verify a true polycythaemia by performing red cell volume studies in all these cases, but a haemoglobin concentration and packed cell volume above these values is unlikely not to represent a true erythrocytosis.

This group included eight patients with long stand- 
ing chronic obstructive airways disease (seven men and one woman of mean age 62 years (range 52-70)); three patients with Eisenmenger's syndrome after congenital heart disease (two men, aged 29 and 33, and one woman aged 50); one man, aged 63, with polycystic kidneys; and one woman, aged 44 , with obstructive sleep apnoea.

All patients with chest and heart disease resulting in polycythaemia induced by hypoxia had arterial oxygen pressure of less than 8.6 kilopascals and arterial oxygen saturations of less than $92 \%$. Below these arterial oxygen values it is thought that hypoxia induced erythrocytosis is likely to develop. ${ }^{3}$

In all patients with secondary polycythaemia the erythrocytosis had been treated only by intermittent venesection.

\section{SELECTION OF NORMAL SUBJECTS}

A normal range of $T$ lymphocyte subset values and helper:suppressor Tlymphocyte ratios was established using 17 healthy medical laboratory staff, none of whom had features to suggest a diagnosis of primary proliferative or secondary polycythaemia.

\section{LYMPHOCYTE SUBPOPULATIONS USING}

\section{MONOCLONAL ANTIBODIES}

Indirect immunofluorescence was carried out on lymphocytes isolated from peripheral blood samples by conventional methods, ${ }^{4}$ using four monoclonal antibodies: CD3 (T, p 19-29), Leu 4, and CD19 (B, p 95) Leu 12 (Becton Dickinson, Middlesex), CD4 (T, p 55), OKT-4 and CD8 (T, p 32-33) OKT-8 (OrthoDiagnostics Systems). CD3 reacts with most peripheral blood lymphocytes that form rosettes with sheep red blood cells but does not react with B lymphocytes. CD19 reacts with all peripheral blood lymphocytes of B cell lineage as defined by the presence of $\kappa$ and $\lambda$ light chains but does not react with T lymphocytes. CD4 and CD8 react with the helper and suppressor subgroups of Tlymphocytes, respectively.

Statistical analysis was performed on the data using Student's $t$ test to compare the mean values of particular variables within each study group.

Patients included in this study were screened to exclude clinical conditions that are known to bring about an increased helper:suppressor Tlymphocyte ratio. ${ }^{4-7}$ This screen comprised a clinical assessment and estimation of liver function tests, thyroid function tests, autoantibody screen, rheumatoid factor, direct Coombs' test, random blood glucose, and gastric intrinsic factor antibody.

\section{Results}

In each patient absolute values were obtained for total lymphocytes, total Tlymphocytes, and helper and suppressor Tlymphocytes from which the helper:suppressor Tlymphocyte ratio was determined.

The mean (SD) absolute lymphocyte count for the normal subjects was $2080(640) \times 10^{6} / 1$. For patients with primary polycythaemia it was $1710(560) \times$ $10^{6} / 1$. There was no significant difference between any of these values. It can therefore be assumed that the observed changes in lymphocyte subgroup numbers in our groups of patients were not influenced by variation in absolute lymphocyte counts.

The table shows the mean (SD) absolute values for T3, T4, and T8 lymphocytes and the helper:suppressor Tlymphocyte ratios within each study group.

The figure represents the helper:suppressor Tlymphocyte ratios obtained within each study group.

There was no significant difference between the mean total $\mathrm{T}$ lymphocyte counts of normal subjects compared with those of patients with either primary or secondary polycythaemia. There was no significant difference between the mean numbers of helper T lymphocytes of normal subjects compared with those of either polycythaemic group.

Mean values for suppressor T lymphocytes were significantly decreased in patients with primary polycythaemia compared with those in normal subjects ( $p$ $<0.001$ ), whereas there was no significant difference in this value between patients with secondary polycythaemia and normal subjects.

As a result of this decrease in suppressor Tlymphocytes in the primary group the helper:suppressor Tlymphocyte ratio was significantly increased in this group compared with that of normal subjects $(p<0.001)$ and patients with secondary polycythaemia $(p<0.01)$. The only

Table Mean (SD) absolute values for T3, T4, T8 lymphocytes and helper:suppressor T lymphocyte ratios

\begin{tabular}{lllll}
\hline & \multicolumn{4}{l}{ Lymphocyte populations $\left(\times 10^{6} / l\right)$} \\
\cline { 2 - 5 } & $T 3$ & $T 4$ & $T 8$ & $T 4: T 8$ \\
\hline Normal subjects & $1488(535)$ & $960(340)$ & $573(229)$ & $1.76(0.5)$ \\
Those with primary polycythaemia & $1238(371)$ & $908(298)$ & $309(131)$ & $3.45(1.72)$ \\
Those with secondary polycythaemia & $1459(450)$ & $934(264)$ & $580(200)$ & $1.69(0.42)$ \\
\hline
\end{tabular}




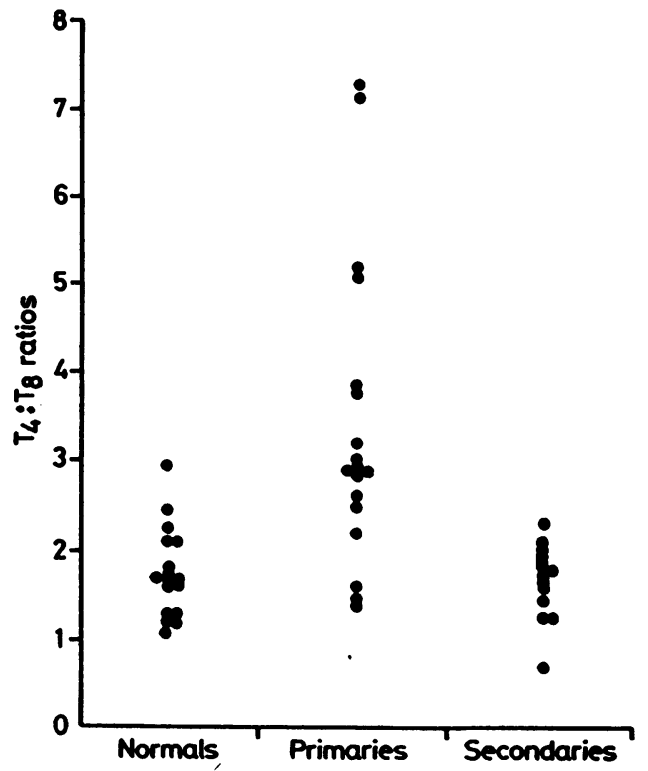

Figure T4:T8 lymphocyte ratios in normal subjects and patients with primary and secondary polycythaemia.

patient in the secondary group suspected of having an inappropriate erythropoietin production causing his polycythaemia was the man with polycystic kidneys who had a helper:suppressor ratio of 1.96.

\section{Discussion}

Our study confirms the finding of Eridani et $a l^{1}$ : helper:suppressor Tlymphocyte ratios are significantly increased in patients with primary proliferative polycythaemia. In addition, we have shown that patients with secondary polycythaemia do not have raised helper:suppressor Tlymphocyte ratios compared with those in normal subjects and that there is a significant difference in the ratio between primary and secondary polycythaemics.

The finding of reduced suppressor T lymphocytes and hence increased helper:suppressor ratios in our patients with primary polycythaemia seemed to be a persistent feature of the condition, remaining uncorrected by previous treatment, such as venesection, ${ }^{32} \mathrm{P}$ injection, or busulphan chemotherapy.

A wide variety of conditions have been reported to cause an increase in the helper:suppressor Tlymphocyte ratio. These include pernicious anaemia (with gastric intrinsic factor antibodies), ${ }^{4}$ newly diagnosed diabetes mellitus, ${ }^{5}$ Hashimoto's thyroiditis, rheumatoid arthritis, Sjogren's syndrome, Wegener's granulomatosis, ${ }^{6}$ autoimmune haemolytic anaemia, seronegative autoimmune chronic active hepatitis, myasthenia gravis, Berger's $\operatorname{IgA}$ deposit nephropathy, membranous glomerulonephritis, and acute episodes of multiple sclerosis. ${ }^{7}$ None of our patients with increased helper:suppressor $T$ cell ratios had evidence of any of these disorders.

Patients often present to haematology clinics with increased haemoglobin concentrations, venous haematocrits, and red cell volume without any other features to suggest a definite diagnosis of primary or secondary polycythaemia.

Modan and Modan ${ }^{8}$ introduced the use of the term benign erythrocytosis for this type of patient in 1968 . In 1979 Pearson and Wetherley-Main ${ }^{9}$ substituted the term idiopathic erythrocytosis. In their study of similar patients $40 \%$ progressed to primary proliferative polycythaemia within six years of follow up from time of diagnosis, so that in their experience the condition was not benign. Eridani ${ }^{1}$ showed that patients fulfilling the criteria of idiopathic erythrocytosis also had increased helper:suppressor $T$ lymphocyte ratios similar to his patients with primary polycythaemia, thereby corroborating the theory that this condition is a primary proliferative disorder.

We conclude that the finding of an increased helper:suppressor $T$ cell ratio of greater than 2.5 implies the likelihood of a primary proliferative disorder in patients with a true polycythaemia, provided other causes of an increased ratio can be excluded. Fourteen of our 18 patients with primary proliferative polycythaemia had helper:suppressor $T$ cell ratios greater than 2.5 compared with none in the group with secondary polycythaemia, but we should point out that one of our normal control subjects did have a ratio of greater than 2.5 .

The two main $T$ cell subsets modulate erythroid progenitor cell growth in vitro. The helper T cells, with the cooperation of monocytes, stimulate progenitor cell growth, whereas the suppressor cells inhibit growth of these cells. ${ }^{10-13}$

Zoumbos $e t$ al $^{14}$ reported that 10 of 12 patients with aplastic anaemia had increased numbers of activated suppressor $T$ cells compared with the numbers in control subjects. Furthermore, these cells were found to be releasing $\gamma$-interferon, which suppressed progenitor cell growth in vitro. The finding of reduced numbers of suppressor $\mathrm{T}$ cells in cases of primary proliferative polycythaemia may be important in the pathogenesis of this disorder. The relative excess of helper $T$ lymphocytes may result in increased burst promoting activity on erythroid progenitor cells, an effect presumably mediated by a relative excess of growth factor substances released by activated helper cells. Helper $\mathrm{T}$ cell lymphokines may also bring about increased sensitivity of later erythroid precursor cells to erythropoietin, an in vitro finding that has been 
to erythropoietin, an in vitro finding that has been noted in patients with primary proliferative polycythaemia. ${ }^{15} 16$

We thank Drs MJ Brown and P Howard for allowing us to investigate their patients and Mrs L Gay and Mrs J Woolley for typing the manuscript.

\section{References}

1 Eridani S, Fiorini GF, Batten E. Peripheral blood lymphocyte sub-populations in polycythaemia and thrombocythaemia. Scand J Haematol 1983;30:479-85.

2 Diem K. Documenta Geigy scientific tables. Sixth ed. Manchester: Geigy Pharmaceutical Company, 1962:623-4.

3 Berlin NI. Diagnosis and classification of polycythaemia. Semin Haematol 1975; 12:339-51.

4 Wodzinski MA, Forrest MJ, Barnett D, Lawrence ACK. Lymphocyte subpopulations in patients with hydroxocobalamin responsive megaloblastic anaemia. J Clin Pathol 1985; 38:582-4.

5 Buschard K, Ropke C, Madsbad S, Mehlsen J, Rygaard J. T lymphocyte sub-sets in patients with newly diagnosed type 1 (insulin-dependent) diabetes: a prospective study. Diabetologia 1983;25(3):247-51.

6 Raeman F, Decock W, De Beukelaar T, De Cree J, Verhaegen H. Enumeration of $\mathrm{T}$ lymphocytes and $\mathrm{T}$ lymphocyte sub-sets in auto immune disease using monoclonal antibodies. Clin Exp Immunol 1981;45:475-9.

7 Bach MA, Bach JF. The use of monoclonal anti-T cell antibodies to study T cell imbalances in human diseases. Review. Clin Exp Immunol 1981;45:449-56.
8 Modan B, Modan M. Benign erythrocytosis. Br J Haematol 1968;14:375-81.

9 Pearson TC, Wetherley-Main G. The course and complications of idiopathic erythrocytosis. Clin Lab Haematol 1979;1: 189-96.

10 Torok-Storb B, Martin P, Hansen JA. Regulation of in vitro erythropoiesis by normal $T$ cells: evidence for two $T$ cell subsets with opposing function. Blood 1981;58:171-4.

11 Reid CDI, Baptista LC, Chanarin I. Erythroid colony growth in vitro from human peripheral blood null cells: Evidence for regulation by T lymphocytes. Br J Haematol 1981;48:155-64.

12 Mangan KF, Chikappa G, Bieler LZ, Scharfman WB, Parkinson DR. Regulation of human blood erythroid burst-forming unit (BFU-E) proliferation by Tlymphocyte sub-populations defined by FC receptors and monoclonal antibodies. Blood 1982;59:990-6.

13 Mangan KF, Hartnett ME, Matis SA, Winkelstein A, Abo T Natural killer cells suppress human erythroid stem cell proliferation in vitro. Blood 1984;63:260-9.

14 Zoumbos NC, Gascon P, Djeu JY, Trost SR, Young NS. Circulating activated suppressor $\mathrm{T}$-lymphocytes in aplastic anaemia. N Engl J Med 1985; 312:257-65.

15 Zanjani ED, Lutton JD, Hoffman R, Wasserman LR. Erythroid colony formation by polycythaemia vera bone marrow in vitro. J Clin Invest 1977;59:841-8.

16 Casadevall N, Vanichenker W, Lacombe C, et al. Erythroid progenitors in polycythaemia vera: demonstration of their hypersensitivity to erythropoietin using serum free cultures. Blood 1982;59:447-51.

Requests for reprints to: Dr ACK Lawrence, Department of Haematology, Northern General Hospital, Herries Road, Sheffield S5 7AU, England. 